\title{
Comportamentos de risco quanto ao Vírus da Imunodeficiência Humana entre caminhoneiros
}

\author{
Human Immunodeficiency Virus risk behavior among truck drivers \\ Comportamientos de riesgo para infección por Virus de la Inmunodeficiencia Humana \\ entre camioneros
}

Krisna Reis Faria'; Renata Letícia Pessoa de Ávila'; ; Taciany Karine de Almeida Ferreiralli; Ering Júnior Barros Coelho ${ }^{I V}$; Martha Elisa Ferreira de Almeida ${ }^{V}$; Helisamara Mota Guedes ${ }^{\text {VI }}$

\begin{abstract}
RESUMO: Os caminhoneiros formam uma categoria profissional que pode contribuir para a disseminação do Vírus da Imunodeficiência Humana (HIV). O objetivo deste estudo foi identificar comportamentos de risco para a infecção pelo HIV em caminhoneiros que trafegavam na BR-381, no Brasil. Utilizou-se um formulário estruturado para identificar alguns dos comportamentos de risco desses profissionais, em 2009. Foram entrevistados 109 caminhoneiros, sendo 99,1\% do sexo masculino; $47,2 \%$ relataram ter baixa escolaridade, $67,9 \%$ eram casados e 32,1\% procuravam parceiras sexuais durante as viagens. Houve diferença significativa com relação à distribuição da frequência do uso do preservativo e o estado civil $(p<0,001)$ e entre o risco ou não de contrair HIV e o fato de escolher ou não parceiras sexuais $(p<0,001)$. Concluiu-se que há necessidade de medidas preventivas de educação para a saúde voltada exclusivamente para esses profissionais, abordando o assunto da transmissão sexual do HIV com ênfase para os riscos à saúde.
\end{abstract}

Palavras-Chave: Comportamento de risco; preservativo; prática em saúde; caminhoneiros.

ABSTRACT: Truck drivers as a professional category can contribute to the spread of the Human Immunodeficiency Virus (HIV). This study aimed to identify risk behaviors for HIV infection among truck drivers traveling highway BR-381. A structured form was used to identify some of these professionals' risk behaviors. In 2009, 109 truck drivers were interviewed: 99.1\% were male, $47.2 \%$ reported little formal education, $67.9 \%$ were married, and $32.1 \%$ sought sexual partners on the road. There were significant differences between the frequency distributions of condom use and marital status $(p<0.001)$, and between being aware or not of the risk of contracting HIV and choosing or not choosing sexual partners $(p<0.001)$. It was concluded that there is need for preventive health education measures directed exclusively to this profession, addressing the issue of the sexual transmission of HIV, and emphasizing the health risks.

Keywords: Risk behavior; condoms; health-related practice; truck drivers.

RESUMEN: Los camioneros forman una categoría profesional que puede contribuir para la diseminación del Virus de Inmunodeficiencia Humana (HIV). El objetivo del estudio fue identificar el comportamiento de riesgo para infección por HIV en camioneros que transitan en la BR-381, en Brasil. Se utilizó un formulario estructurado para identificar algunos de los comportamientos de riesgo de esos profesionales, en 2009. Fueron entrevistados 109 camioneros, siendo 99,1\% hombres; $47,2 \%$ reportaron tener bajo nivel de educación, $67,9 \%$ eran casados y $32,1 \%$ buscaban parejas sexuales durante el viaje. Hubo diferencia significativa con relación a la distribución de la frecuencia del uso de preservativo y el estado civil $(p<0,001)$, y entre el riesgo o no de contraer HIV, y el hecho de escoger o no parejas sexuales $(p<0,001)$. Se concluye que hay necesidad de medidas preventivas de educación para la salud, orientadas exclusivamente para esos profesionales, abordando el asunto de la transmisión sexual del HIV principalmente para los riesgos a la salud.

Palabras Claves: Comportamiento de riesgo; condones; práctica en salud; camioneros.

\section{INTRODUÇÃO}

O Vírus da Imunodeficiência Humana (HIV) foi identificado em 1980, sendo a doença denominada de Síndrome da Imunodeficiência Adquirida (AIDS). Segundo estimativas do Departamento de DST, Aids e Hepatites Virais, aproximadamente 718.000 pessoas vivem com HIV/AIDS no Brasil, sendo que 265.698 vieram a óbitos. No ano de 2012, foram notificados 39.185 casos da doença no Brasil ${ }^{1}$.

\footnotetext{
IEnfermeira. Graduada pelo Centro Universitário do Leste de Minas Gerais, Unileste-Minas Gerais. Brasil. E-mail: monografiaenf_re.krisna@yahoo.com.br "Enfermeira. Graduada pelo Centro Universitário do Leste de Minas Gerais, Unileste- Minas Gerais. Brasil. E-mail: renata.decalazans@facebook.com IIIEnfermeira. Graduada pelo Centro Universitário do Leste de Minas Gerais, Unileste- Minas Gerais. Brasil. E-mail: taciany.drumond@hotmail.com

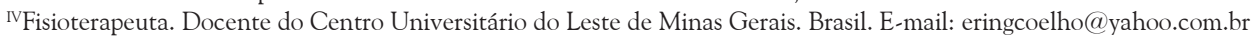

vNutricionista. Doutora em Agroquímica pela Universidade Federal de Lavras. Professora Adjunta do Instituto de Ciências Biológicas e da Saúde da Universidade Federal de Viçosa, Campus de Rio Paranaíba. Minas Gerais. Brasil. E-mail: martha.almeida@ufv.br

${ }^{V I}$ Enfermeira. Doutora em Enfermagem pela Universidade Federal de Minas Gerais. Professora Adjunta do Departamento de Enfermagem da Universidade Federal do Vale do Jequitinhonha e Mucuri. Diamantina, Minas Gerais, Brasil. E-mail: helisamaraguedes@gmail.com
} 
Embora a maioria dos casos de AIDS esteja registrada na região sudeste ${ }^{2}$, a epidemia encontra-se em expansão nas regiões Norte e Nordeste, enquanto tem diminuído de forma significativa no Sudeste ${ }^{3}$. Os principais meios de contaminação são através do contato sexual sem proteção, uso de drogas injetáveis, transfusões, utilização de material perfurocortante contaminado e da mãe para o filho durante o parto e a amamentação ${ }^{4}$.

A busca pela prática sexual segura contribui para amenizar o risco de contaminação desta doença, e dentro deste contexto o enfermeiro pode desenvolver ações que conscientize as diferentes parcelas da população sobre a importância da prevenção. Diante disso, o estudo teve como objetivo identificar comportamentos de risco para a infecção pelo HIV em caminhoneiros que trafegavam na BR-381.

\section{REVISÃo DE LITERATURA}

Os caminhoneiros são um grupo com comportamento de risco para a contaminação pelo HIV, pois apresentam hábitos de busca de parceiras sexuais eventuais durante as viagens de trabalho, tendo suas práticas efetuadas, na maioria das vezes, sem o uso do preservativo ${ }^{5}$. Geralmente estes profissionais têm conhecimento da prevenção do HIV, mas dependendo da parceira eles realizam atos sexuais sem o uso do preservativo ${ }^{6}$.

Esse grupo profissional também está exposto ao risco de contrair Doenças Sexualmente Transmissíveis (DST), e se infectados podem transmiti-las para outras pessoas, pois viajam por diversas cidades e/ou países, e geralmente não participam das atividades de práticas de saúde difundidas nas unidades básicas de saúde ${ }^{5}$.

Desta maneira, ações de prevenção da doença devem ser realizadas, uma vez que os enfermeiros irão vivenciar com os pacientes infectados o sofrimento resultante da doença, em alguns casos a proximidade da morte e o processo de morrer, além dos riscos de contaminação?

\section{Metodologia}

Trata-se de uma pesquisa transversal com abordagem quantitativa, realizada no Auto Posto Torque Diesel LTDA, situado na BR-381, em Timóteo, MG. Esta escolha foi baseada na presença dos seguintes setores: serviço de abastecimento, borracharia, loja de peças, troca de óleo, restaurante, lanchonete, banheiros com duchas dentro do próprio posto, presença de uma transportadora de cargas onde se concentravam muitos caminhoneiros a espera de cargas e um amplo estacionamento para o descanso desses profissionais.

A amostra foi calculada pelo programa Diman 1.0 correspondendo a um total de 109 caminhoneiros que trafegavam na BR-381. Os critérios de inclusão dos pesquisados foram: um ano ou mais de exercício da profissão e possuir idade $\geq 21$ anos, uma vez que a Legislação do Código Nacional de Trânsito Brasileiro determina essa idade como necessária para a habilitação dos dirigentes de carretas.

O estudo foi aprovado pelo Comitê de Ética em Pesquisa do Centro Universitário do Leste de Minas Gerais - Unileste/MG, parecer no 13.55.08, e contemplou a Resolução no 196/96 que regulamentava pesquisas envolvendo seres humanos do Conselho Nacional de Saúde ${ }^{8}$.

A coleta de dados ocorreu no mês de junho de 2009. Foi aplicado um pré-teste com 10 caminhoneiros e feitas as adaptações necessárias no instrumento de coleta de dados, que foi realizada através de um formulário estruturado para avaliar os aspectos sociodemográficos, práticas sexuais, conhecimento sobre HIV/AIDS, uso de preservativos e a percepção do risco de adquirir o HIV e a AIDS. O instrumento de coleta de dados possuía 10 questões, cuja aplicação, de forma individualizada, durou em média 15 minutos. Em todos os itens os participantes podiam marcar mais de uma resposta. Esse profissional foi abordado de forma individual em um local reservado.

Utilizou-se a estatística analítica para as variáveis categóricas. Para verificar a associação entre as variáveis do estudo foi utilizado o teste qui-quadrado no programa Statistical Package for Social Sciences (SPSS), com a significância de 5\%.

\section{Resultados e Discussão}

Fizeram parte do estudo 109 caminhoneiros, $108(99,1 \%)$ do sexo masculino e $1(0,9 \%)$ do feminino. A idade mínima foi de 22 anos e a máxima de 64, com uma média de 39,6 anos, sendo que $19(17,4 \%)$ dos participantes tinham de 19 a 29 anos; 36(33\%) de 30 a 39 anos; 35(32,1\%) de 40 a 49 anos; 16(14,7\%) de 50 a 59 anos e $3(2,8 \%)$ eram idosos.

O tempo mínimo de profissão foi de 1 ano e o máximo de 45 , com uma média de 16,7 anos. $\mathrm{O}$ tempo mínimo fora de casa foi de zero $(0)$ e o máximo de 40 dias, com uma média de 8,1 dias. Observou-se que $25(23,9 \%)$ dos avaliados cursaram todo o Ensino Fundamental, 21(19,3\%) terminaram o Ensino Médio e $2(1,8 \%)$ tinham o Curso Superior completo. A baixa escolaridade pode impactar diretamente sobre os hábitos de saúde do indivíduo ${ }^{6,9,10}$, uma vez que tal fato leva as pessoas a não fazerem do preservativo um hábito nas suas relações sexuais, aumentando assim o risco de contaminação pelo HIV.

Dos entrevistados, 74(67,9\%) eram casados e $24(22 \%)$ eram solteiros. Foi relatado por 63(85,2\%) dos casados a ausência de uso de preservativo com suas parceiras e $13(54,2 \%$ ) dos solteiros faziam uso do pre- 
servativo. Houve diferença significativa com relação à distribuição da frequência do uso do preservativo e o estado civil $(p<0,001)$, conforme mostra a Tabela 1 .

Em outro estudo observou-se que 77\% daqueles que buscavam as parceiras sexuais eram casados, e os contatos ocorriam com parceiras variadas, sendo que $67 \%$ dos solteiros também tinham parceiras variadas ${ }^{6}$.

Foram encontradas diferenças significativas $(p=0,026)$ com relação ao uso de preservativos e a procura por parceira sexual durante as viagens. Entre aqueles que citaram possuir parceiras fixas durante as viagens, 89(94,7\%) relataram que não usavam preservativos, uma vez que as conheciam.

Pesquisa feita com a população em geral ${ }^{11}$ mostrou um aumento da exposição às DST/AIDS, tendo em vista que os parceiros sexuais tendem a interromper o uso de preservativo depois de algum tempo de relacionamento, por passarem a sentir confiança no outro.

Estudo realizado com caminhoneiros encontrou uma baixa frequência de uso de preservativos, pois somente $14,6 \%$ os utilizavam de forma rotineira durante as relações sexuais com as parceiras fixas. $\mathrm{O}$ uso habitual de preservativos com parceiras ocasionais, e seu uso na última relação sexual, foi referido por aproximadamente $50 \%$ dos caminhoneiros ${ }^{12}$.

Dado divergente ao deste estudo foi encontrado entre os caminhoneiros de Campinas, no qual foi observado que existe uma consciência quanto a importância do uso do preservativo nas práticas sexuais, sendo que dentre os 47 (94\%) daqueles que referiram possuir parceiros eventuais, apenas 3(6\%) nunca usaram o preservativo nessas relações ${ }^{13}$. Entretanto, no estudo realizado na África do Sul ${ }^{14}$ foi observado que $66 \%$ dos caminhoneiros já tinham uma DST, 37\% sempre paravam para relações sexuais eventuais ao longo da rota e $29 \%$ nunca usavam preservativo nas relações casuais. No estudo realizado em 2000 pela Coordenação Nacional de DST/AIDS do Ministério da Saúde ${ }^{15}$, com caminhoneiros de todo Brasil, foi observado que 30\% não faziam uso de preservativo em relações sexuais com parceiros eventuais. Entre os frequentadores de um motel identificou-se que 70,8\% consideraram remota a possibilidade de contaminação pelo HIV, pois a maioria de suas parceiras eram fixas ${ }^{11}$. Neste estudo, foram encontradas diferenças significativas no uso de preservativo entre os participantes que afirmaram ter parceiro fixo e não fixo $(\mathrm{p}<0,001)$.

TABELA 1: Distribuição do uso de preservativo segundo o estado civil, parceiras eventuais, parceiros fixos e risco de infectar. Timóteo, MG, 2009.

\begin{tabular}{|c|c|c|c|c|c|c|c|}
\hline & \multirow[b]{2}{*}{ Variáveis } & \multicolumn{5}{|c|}{ Uso de preservativo } & \multirow{2}{*}{$\begin{array}{l}\text { Valor } \\
\text { de } p\end{array}$} \\
\hline & & $\begin{array}{c}\text { Não } \\
\text { usava }\end{array}$ & $\begin{array}{c}\text { As vezes } \\
\text { usava }\end{array}$ & $\begin{array}{c}\text { Raramente } \\
\text { usava }\end{array}$ & $\begin{array}{c}\text { Sempre } \\
\text { usava }\end{array}$ & Total & \\
\hline \multirow[t]{5}{*}{ Estado civil } & Casado & $\begin{array}{c}52 \\
(85,2 \%)\end{array}$ & $\begin{array}{c}3 \\
(75,0 \%)\end{array}$ & $\begin{array}{c}8 \\
(44,4 \%)\end{array}$ & $\begin{array}{c}11 \\
(42,3 \%)\end{array}$ & $\begin{array}{c}74 \\
(67,9 \%)\end{array}$ & \\
\hline & Solteiro & $\begin{array}{c}5 \\
(8,2 \%)\end{array}$ & $\begin{array}{c}1 \\
(25,0 \%)\end{array}$ & $\begin{array}{c}4 \\
(22,2 \%)\end{array}$ & $\begin{array}{c}14 \\
(53,8 \%)\end{array}$ & $\begin{array}{c}24 \\
(22,0 \%)\end{array}$ & \\
\hline & Divorciado & $\begin{array}{c}3 \\
(4,9 \%)\end{array}$ & - & $\begin{array}{c}5 \\
(27,8 \%)\end{array}$ & - & $\begin{array}{c}8 \\
(7,3 \%)\end{array}$ & $0,000^{*}$ \\
\hline & Amasiado & $\begin{array}{c}1 \\
(1,6 \%)\end{array}$ & - & $\begin{array}{c}1 \\
(5,6 \%)\end{array}$ & - & $\begin{array}{c}2 \\
(1,8 \%)\end{array}$ & \\
\hline & Viúvo & - & - & - & $\begin{array}{c}1 \\
(3,8 \%)\end{array}$ & $\begin{array}{c}1 \\
(0,9 \%)\end{array}$ & \\
\hline \multirow{4}{*}{$\begin{array}{l}\text { Procurava } \\
\text { parceiras } \\
\text { durante as } \\
\text { viagens }\end{array}$} & Sempre & $\begin{array}{c}1 \\
(1,6 \%)\end{array}$ & - & $\begin{array}{c}3 \\
(16,7 \%)\end{array}$ & $\begin{array}{c}1 \\
(3,8 \%)\end{array}$ & $\begin{array}{c}5 \\
(4,6 \%)\end{array}$ & \\
\hline & Esporadicamente & $\begin{array}{c}15 \\
(24,6 \%)\end{array}$ & $\begin{array}{c}3 \\
(75,0 \%)\end{array}$ & $\begin{array}{c}5 \\
(27,8 \%)\end{array}$ & $\begin{array}{c}7 \\
(26,9 \%)\end{array}$ & $\begin{array}{c}30 \\
(27,5 \%)\end{array}$ & $0,026^{*}$ \\
\hline & Nunca & $\begin{array}{c}45 \\
(73,8 \%)\end{array}$ & $\begin{array}{c}1 \\
(25,0 \%)\end{array}$ & $\begin{array}{c}10 \\
(55,6 \%)\end{array}$ & $\begin{array}{c}16 \\
(61,5 \%)\end{array}$ & $\begin{array}{c}72 \\
(66,1 \%)\end{array}$ & \\
\hline & Resposta incompleta & - & - & - & $\begin{array}{c}2 \\
(7,7 \%)\end{array}$ & $\begin{array}{c}2 \\
(1,8 \%)\end{array}$ & \\
\hline \multirow[t]{2}{*}{ Parceira fixa } & Sim & $\begin{array}{c}58 \\
(95,1 \%)\end{array}$ & $\begin{array}{c}4 \\
(100 \%)\end{array}$ & $\begin{array}{c}18 \\
(100 \%)\end{array}$ & $\begin{array}{c}14 \\
(53,8 \%)\end{array}$ & $\begin{array}{c}94 \\
(86,2 \%)\end{array}$ & $0,000^{*}$ \\
\hline & Não & $\begin{array}{c}3 \\
(4,9 \%)\end{array}$ & - & - & $\begin{array}{c}12 \\
(46,2 \%)\end{array}$ & $\begin{array}{c}15 \\
(13,8 \%)\end{array}$ & \\
\hline \multirow[t]{3}{*}{$\begin{array}{l}\text { Risco de se } \\
\text { infectar }\end{array}$} & Sim & $\begin{array}{c}22 \\
(36,1 \%)\end{array}$ & $\begin{array}{c}3 \\
(75 \%)\end{array}$ & $\begin{array}{c}9 \\
(50 \%)\end{array}$ & $\begin{array}{c}17 \\
(65,4 \%)\end{array}$ & $\begin{array}{c}51 \\
(46,8 \%)\end{array}$ & \\
\hline & Não & $\begin{array}{c}36 \\
(59 \%)\end{array}$ & $\begin{array}{c}1 \\
(25 \%)\end{array}$ & $\begin{array}{c}9 \\
(50 \%)\end{array}$ & $\begin{array}{c}9 \\
(34,6 \%)\end{array}$ & $\begin{array}{c}55 \\
(50,5 \%)\end{array}$ & 0,163 \\
\hline & Resposta incompleta & $\begin{array}{c}3 \\
(4,9 \%)\end{array}$ & - & - & - & $\begin{array}{c}3 \\
(2,8 \%)\end{array}$ & \\
\hline
\end{tabular}


A confiança na parceira estável (esposa e amantes) contribui para a não utilização de preservativos. Este comportamento de risco está presente na população como um todo, já que a análise de regressão logística de um estudo realizado em motéis revelou que o fator que mais contribuiu para a não utilização de preservativos foi a presença de parceiras fixas ${ }^{16}$. Neste estudo identificou-se que entre as parceiras fixas havia um uso mínimo do preservativo, independentemente do tipo de prática e com as parceiras frequentes o uso de preservativo era maior, tanto na relação vaginal $(56,6 \%)$ quanto na anal (45\%). Com as parceiras casuais, o uso de preservativo também era frequente tanto na relação vaginal (67\%) quanto na anal (54\%). Demonstrando que a parceira fixa é a mais vulnerável no que se refere à infecção pelo HIV ou qualquer outra DST $^{17}$. No estudo com caminhoneiros de rota curta observou-se que a prevenção da AIDS foi ressaltada pelo uso da camisinha nas relações extraconjugais e pela fidelidade da esposa ${ }^{18}$.

Neste estudo, tanto os caminhoneiros que usavam o preservativo quanto os que não usavam, relataram ter risco de contrair o HIV, sendo portanto, um grupo com comportamento de risco para adquirir a AIDS e também outras DST.

Os parceiros fixos atribuem o não uso do preservativo ao preconceito que o mesmo carrega do seu uso estar associado a prostituição, promiscuidade e a relações extraconjugais. Porém, a não utilização de preservativo com parceiros fixos é muitas vezes considerada pelos casais como uma forma de demonstrar fidelidade. A não utilização de preservativos entre casais de parceiros fixos, também está relacionado a argumentos como o uso de outros métodos contraceptivos; o fato do(a) companheiro(a) não gostar de utilizá-lo; a realização prévia de exames anti-HIV o que confere segurança à relação; além da própria submissão feminina nas relações conjugais ${ }^{19}$.

A concepção de que não havia probabilidade de se contaminar pelo HIV foi relatado por 36(65,5\%) caminhoneiros que não escolhiam as parceiras para se relacionar sexualmente. Houve diferença significativa entre o risco ou não de contrair HIV e o fato de escolher as parceiras sexuais $(p<0,001)$, conforme mostra a Tabela 2.

Observou que existe um desconhecimento teórico desses motoristas ao inferirem que a aparência física é capaz de dizer se existe o risco de transmissão do HIV. No estudo realizado com caminhoneiros, 69\% achavam que não estavam em risco, sendo que $40 \%$ afirmaram estar protegidos por terem parceiras fixas, $31 \%$ ressaltaram não ter risco algum de se infectar e $27 \%$ não tinha medo de contrair a doença ${ }^{20}$. Possuir conhecimento das formas de transmissão do HIV não assegura o uso do preservativo, pois a prevenção da contaminação por este vírus precisa ser de interesse do indivíduo ${ }^{11}$.

Os homens estão altamente expostos, uma vez que muitos possuem múltiplas parceiras e não usam preservativo, existindo a percepção de que a AIDS se limita a determinados grupos, concebendo-a como uma doença fora de seu contexto. Assim, medidas preventivas acabam não sendo adotadas por esses indivíduos que não se consideram um grupo de risco ${ }^{21}$.

Os caminhoneiros formam uma categoria profissional que pode contribuir para a disseminação do HIV, pois além de viajarem continuamente por diversas regiões estão expostos ao risco de contrair várias DST, uma vez que praticam o ato sexual sem o uso de preservativos com parceiras que eles consideram amigas e livres do HIV $^{20}$.

Dos entrevistados, apenas $31(28,4 \%)$ tinham feito o teste de HIV, sendo que 39(35,5\%) demonstraram conhecimento sobre o seu modo de transmissão, $22(20,1 \%)$ informaram corretamente os modos de prevenção, 28(25,4\%) relataram pouca informação e $20(19 \%)$ destacaram que a AIDS é uma doença que pode levar a morte. Entre os métodos de prevenção, o preservativo foi mencionado por $89(81,7 \%)$ dos entrevistados. Foi relatado por $90(82,6 \%)$ participantes que as informações sobre o HIV foram transmitidas pela televisão, conforme mostra a Figura 1.

TABELA 2: Distribuição do risco de adquirir HIV e a escolha da parceira durante as viagens. Timóteo, MG, 2009.

\begin{tabular}{|c|c|c|c|c|c|}
\hline \multirow{2}{*}{$\begin{array}{l}\text { Escolhe a(o) } \\
\text { parceira(o) }\end{array}$} & \multicolumn{4}{|c|}{ Risco } & \multirow{2}{*}{$\begin{array}{c}\text { Valor de } \\
p\end{array}$} \\
\hline & Sim & Não & $\begin{array}{c}\text { Não } \\
\text { respondeu }\end{array}$ & Total & \\
\hline Sim & $\begin{array}{c}19 \\
(37,3 \%)\end{array}$ & $\begin{array}{c}19 \\
(34,5 \%)\end{array}$ & $\begin{array}{c}1 \\
(33,3 \%)\end{array}$ & $\begin{array}{c}39 \\
(35,8 \%)\end{array}$ & \\
\hline Não & $\begin{array}{c}32 \\
(62,7 \%)\end{array}$ & $\begin{array}{c}36 \\
(65,5 \%)\end{array}$ & $\begin{array}{c}1 \\
(33,3 \%)\end{array}$ & $\begin{array}{c}69 \\
(63,3 \%)\end{array}$ & $\left.0,000{ }^{*}\right)$ \\
\hline Não respondeu & - & - & $\begin{array}{c}1 \\
(33,3 \%)\end{array}$ & $\begin{array}{c}1 \\
(0,9 \%)\end{array}$ & \\
\hline
\end{tabular}

(*) Diferença estatística a $p<0,05$. 


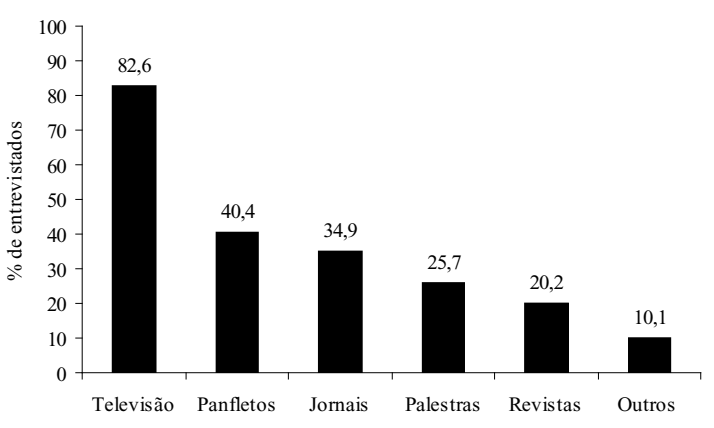

FIGURA 1: Distribuição percentual dos meios de informação sobre o HIV de acordo com os caminhoneiros. Timóteo, MG, 2009.

Outro estudo mostrou que a televisão foi a principal fonte de informação quanto à transmissão do HIV; foi observado que 50,4\% dos entrevistados nunca participaram de palestras sobre a prevenção do HIV, por serem realizadas em locais distantes do seu trabalho, o que dificultava o acesso9 ${ }^{9}$. Entretanto, foi relatado por $88(81 \%)$ caminhoneiros deste estudo o desejo de participação em palestras sobre esse tema, bem como em campanhas educativas de distribuição gratuita de preservativos nos locais de espera de cargas e descargas e nos postos de combustíveis.

A maioria dos entrevistados desta pesquisa tinha comportamento de riscos, pois nunca havia feito o exame de HIV. Tal dado é similar àqueles de outro estudo, no qual $67,1 \%$ não souberam informar se haviam feito o exame, o que levou os autores a concluírem que possivelmente eles não realizaram o teste ${ }^{9}$. Outros caminhoneiros avaliados possuíam conhecimento sobre DST e AIDS, sendo que a maioria não fazia uso de preservativos, o que poderia contribuir para a aquisição de DST ${ }^{22}$. Alguns aspectos culturais tornam o homem mais vulnerável às práticas de risco para as DST e AIDS, por reforçarem sentimentos e comportamentos tais como sentir-se forte, imune a doenças; ser impetuoso e correr riscos; ser incapaz de recusar uma mulher; considerar que o homem tem mais necessidade de sexo do que a mulher e de que esse desejo é incontrolável ${ }^{23}$. Diante do exposto, são necessárias ações de saúde em seu ambiente de trabalho.

Por ser este um grupo populacional com elevada vulnerabilidade para a infecção pelo HIV, tem sido sugerido a implementação de planejamento estratégico de ações quanto ao reconhecimento dessa condição, que é influenciada pelos fatores individuais, culturais, sociais e econômicos, para compreender a dinâmica social e epidemiológica da infecção desse vírus, e assim evitar a contaminação de outros indivíduos ${ }^{24,25}$.

Ao analisar o conhecimento das formas de prevenção do HIV, os dados ressaltam a necessidade de informações para esse público quanto aos riscos de infecção, destacando as intervenções educativas para que todos eles repensem suas práticas sexuais.
Este estudo apresentou como limitação o fato de os dados representarem a realidade dos motoristas de um único posto de combustível na BR-381, o que impossibilita sua validade externa. Entretanto, ele aponta diferentes comportamentos de risco, aos quais os caminhoneiros estão expostos, e que devem ser contemplados nas intervenções das políticas públicas.

\section{ConClusão}

A maioria dos caminhoneiros possuía baixa escolaridade, procurava parceiras sexuais durante as viagens e não fazia uso habitual de preservativo com as parceiras fixas. Tais comportamentos de riscos favorecem a exposição ao HIV e às DST, pois mesmo os métodos preventivos sendo conhecidos pela maioria deles, não eram praticados em muitas situações.

Ações preventivas de saúde devem ser realizadas no seu ambiente de trabalho, através de palestras educativas, principalmente para os profissionais que relatam possuir pouco tempo para o acesso aos meios de assistência.

\section{REFERÊNCIAS}

1.Ministério da Saúde (Br). Secretaria de Vigilância em Saúde. Departamento de DST, Aids e Hepatites Virais. Boletim Epidemiologia - AIDS e DST. Brasília (DF): Editora MS; 2013.

2.Ministério da Saúde (Br). Aprenda sobre HIV e AIDS. AIDS no Brasil. Brasília (DF): Editora MS; 2014. [citado em 21 out 2014]. Disponível em: http://www.aids.gov.br/ pagina/dados-e-pesquisas.

3.Teixeira TRA, Gracie R, Malta MS, Bastos FI. Social geography of AIDS in Brazil: identifying patterns of regional inequalities. Cad Saúde Pública. 2014;30:259-71. 4.Ministério da Saúde (Br). Aprenda sobre HIV e AIDS. Formas de contágio. Brasília (DF): Editora MS; 2014. [citado em 21 out 2014]. Disponível em: http://www. aids.gov.br/pagina/formas-de-contagio.

5.Botelho SSP, Guedes HM, Paes MSL. Uso do "rebite" entre caminhoneiros que trafegam na BR-381 do interior do Estado de Minas Gerais. Enfermagem Brasil. 2008; 7:134-40.

6.Nascimento E. Desenvolvimento de pesquisa-ação com caminhoneiros de estrada: trabalhando na problematização as questões voltadas à sexualidade, DTS/ Aids e drogas [tese de doutorado]. Ribeirão Preto (SP): Universidade de São Paulo; 2003.

7.Ferreira RES, Souza NVDO, Gonçalves FGA, Santos DM, Pôças CRMR. O trabalho de enfermagem com clientes HIV/AIDS: potencialidade para o sofrimento psíquico. Rev enferm UERJ. 2013; 21:477-82.

8.Ministério da Saúde (Br). Conselho Nacional de Saúde. Resolução no 196/96, sobre pesquisa envolvendo seres humanos. Brasília (DF): Ministério da Saúde; 1996.

9.Silva MV. Aferição de conhecimento sobre HIV em caminhoneiros na prevenção da AIDS. Rev Enferm Atual. 2008; 43:23-8. 
10.Guedes HM, Brum KA, Costa PA, Almeida MEF. Fatores de risco para o desenvolvimento de hipertensão arterial entre motoristas caminhoneiros. Cogitare Enferm. 2010; 15:652-8.

11.Guedes HM, Silva GA, Salgado PO, Chianca TCM, Alves M. Uso de preservativo entre frequentadores de um motel. Rev enferm UERJ. 2013; 21:241-6.

12. Teles AS, Matos MA, Caetano KAA, Costa LA, França DDS, Pessoni GC, Brunini SM, Martins RMB. Comportamentos de risco para doenças sexualmente transmissíveis em caminhoneiros no Brasil. Rev Panam Salud Publica. 2008; 24:25-30.

13.Masson VA, Monteiro MI. Vulnerabilidade à doenças sexualmente transmissíveis/AIDS e uso de drogas psicoativas por caminhoneiros. Rev Bras Enferm. 2010; 63:79-83.

14.Ramjee G, Gouws E. Prevalence of HIV among truck drivers visiting sex workers in Kwazulu-Natal, South Africa. Sex Transm Dis. 2002; 29:44-9.

15.Fonseca MG. Caminhoneiros e o conhecimento sobre os meios de transmissão do HIV. Boletim Epidemiol AIDS. 2001; 14:49-56.

16.Guedes HM, Cabral LOC; Costa MVB, Reis AF, Pereira SG, Oliveira-Ferreira, F. Comportamentos de risco frente ao vírus da imunodeficiência humana entre frequentadores de motéis. Rev Latino-Am Enfermagem. 2012; 20:536-42.

17.Ministério da Saúde (Br). Metas e compromissos assumidos pelos Estados-Membros na sessão especial da Assembleia Geral das Nações Unidas sobre HIV/AIDS. UNGASS - HIV/AIDS. Brasília (DF): Editora MS; 2010.
18.Sousa LMS, Silva LS, Palmeira AT. Representações sociais de caminhoneiros de rota curta sobre HIV/AIDS. Psicol Soc. 2014; 26:346-55.

19.Maia C, Guilhem D, Freitas D. Vulnerabilidade ao HIV/AIDS de pessoas heterossexuais casadas ou em união estável. Rev Saude Publica. 2008; 42:1-6.

20.Villarinho L, Bezerra I, Lacerda R, Latorre MRDO, Paiva V, Stall R, Hearst N. Caminhoneiros de rota curta e sua vulnerabilidade ao HIV, Santos, SP. Rev Saude Publica. 2002; 36:61-7.

21.Vieira EM, Villela WV, Réa MF, Fernandes MEL, Franco E, Ribeiro G. Alguns aspectos do comportamento sexual e prática de sexo seguro em homens de Município de São Paulo. Cad Saúde Pública. 2000; 16:997-1009. 22.Santos CRL, Bueno SMV. Pesquisa-ação com caminhoneiros sobre sexualidade e DST-AIDS. J Bras Doenças Sex Trans. 1999; 11:11-21.

23. Guerriero I, Ayres JRCM, Hearst N. Masculinidade e vulnerabilidade ao HIV de homens heterossexuais, São Paulo, SP. Rev Saude Publica. 2002; 36:50-60.

24.Lazzarotto AR, Santos VS, Reichert MT, Quevedo DM, Fossatti P, Santos GA, Calvetti PÜ, Sprinz E. Oficinas educativas sobre HIV/AIDS: uma proposta de intervenção para idosos. Rev Bras Geriatr Gerontol. 2013; 16:833-43.

25.Pereira BS, Costa COM, Amaral MTR, Costa HS, Silva CAL, Sampaio VS. Fatores associados à infecção pelo HIV/AIDS entre adolescentes e adultos jovens matriculados em Centro de Testagem e Aconselhamento no Estado da Bahia, Brasil. Ciênc Saúde Coletiva. 2014; 19:747-58. 